\title{
Dental health status and oral health behaviours of patients with facial burn in Pakistan
}

\author{
Farooq Ahmad Chaudhary ${ }^{1,2}$, Basaruddin Ahmad ${ }^{2^{*}}$ (i) and Ulfat Bashir ${ }^{3}$
}

\begin{abstract}
Background: There is a limited understanding about the oral health of patients with facial burn, hence the aim was to describe the oral health status and the related risks factors.

Methods: This cross-sectional study had randomly and systematically recruited facial burn patients from the Burn Care Center, Pakistan Institute of Medical Sciences, Islamabad, from June of 2016 to July of 2017. Intraoral examination recorded the DMFT, CPI and OHI-S. Information on the socio-demographic status, self-perceived oral health, oral health behaviours were collected using a self-administered questionnaire and; the burn characteristics were obtained from the patients' medical record. The t-test, ANOVA, SLR, and chi-square test were used to examine the relationship between oral health and each factor. A parameter was derived from the clinical indices using the principal component analysis and used in the multiple linear regression analysis to determine the important factors associated with oral health status.
\end{abstract}

Results: A total of 271 burn patients (69\% female and 31\% male) had participated in the study. All of the participants had caries with mean DMFT $=10.96$ (95\%Cl: 10.67, 11.25). There were 59.0\% (95\%Cl: 53.15, 64.93\%) and $66.1 \%$ (95\%Cl: 60.38, 71.73\%) of the participants who had periodontitis and poor oral hygiene respectively. About 79 and $80 \%$ of the participants rated their dental and periodontal status as poor. About $78 \%$ reported brushing once daily and $89 \%$ did not practice regular dental visit. The DMFT, CPI and OHI-S were associated with the burn characteristics and oral health behaviours $(p<0.05)$. Dental anxiety, cost and social issues were the most cited reasons for not utilising oral health services. Greater burn severity, the longer time elapsed since the burn incident, and dental anxiety were associated with poorer oral health status and; brushing twice or more and regular dental visit, with better status $(p<0.01)$.

Conclusion: Patients with oro-facial burn injury had a generally poor oral health and, the risks are greater in those with a more severe and wider area of injury, the longer time elapsed since the burn incident and dental anxiety; but a good oral hygiene practice and regular dental visits were protective against the risk.

Keywords: Burn, Oral health, Behaviours, Psychological, DMFT, CPI, OHI-S, Self-perceived

\footnotetext{
* Correspondence: basaruddin@usm.my

${ }^{2}$ School of Dental Sciences, Universiti Sains Malaysia, Kubang Kerian, Malaysia

Full list of author information is available at the end of the article
}

(c) The Author(s). 2019 Open Access This article is distributed under the terms of the Creative Commons Attribution 4.0 International License (http://creativecommons.org/licenses/by/4.0/), which permits unrestricted use, distribution, and reproduction in any medium, provided you give appropriate credit to the original author(s) and the source, provide a link to the Creative Commons license, and indicate if changes were made. The Creative Commons Public Domain Dedication waiver (http://creativecommons.org/publicdomain/zero/1.0/) applies to the data made available in this article, unless otherwise stated. 


\section{Background}

Burn injuries may have devastating impacts on a victim and is one of the major public health problems in the developing world [1, 2]. A burn to the oro-facial region may have compounding impacts that include physical changes to the oral-motor structure, morphology, mobility and oral functions. Oral burn contracture, a condition where the skin tightens as a result of scarring, may lead to microstomia, which can affect the ability to perform daily activities such as mastication, swallowing and speech [3-6]. Other complications include the loss of facial and labial sensation, inadequate oral competence which cause chronic drooling and, difficult access for oral hygiene care or dental treatment [7]. The effects of oro-facial changes were not limited to the physical aspects but also on the psycho-social quality of life as it impacts growth, eating, speaking, self-esteem, personal relationships, financial, social interactions and social well-being $[8,9]$.

Technological advancement in burn care techniques to improve oral health related quality of life such as corrective surgery, implants, and complex prostheses; in tandem with psychological rehabilitation, could improve the survival rate and coping with the impact of the burn incident, particularly in the severely burned cases [10]. These, however, benefit the victims in the developed countries more than those in the other parts of the world because of the availability of services and cost. Nevertheless, the demand and expectation for a better care of burn victims and to improve the general and oral health related quality of life is likely to continue to increase and hopefully it would include the less affluent groups in the future $[11,12]$. Because of that, it is essential to understand the burden of oral health problems in the oro-facial burn community in order to plan the much-needed rehabilitation and treatment services. However, there is currently little description of the oral health burden of that community in the literature, hence the aim to describe the oral health problems and the factors that influence their oral health condition.

\section{Methods}

This cross-sectional study was carried out at the Burn Care Center, Pakistan Institute of Medical Sciences in Islamabad, Pakistan after the ethical approval and study protocol was approved (Reference no. F.1-1/2015/ERB/ SZABMU). Burn patients who were visiting the centre for follow-up were included in the study if they were over 15 years-old, sustained the injury over one year, had a greater than $10 \%$ total body surface area (TBSA) affected by the burn which involved the face and neck region and, able feed exclusively by mouth [13]. They were systematically and randomly recruited during their follow-up visits at the centre. Sample size was calculated at $N=270$ based on the prevalence of caries $(61.4 \%)$ and periodontal disease $(34.5 \%)$ in the region at $95 \%$ confidence level and $10 \%$ precision $[14,15]$.

Consented patients were subjected to an intraoral examination and self-administered questionnaires and, assisted if required. One investigator had carried out all the examination in a room with the patient sitting on a reclined chair and under adequate lighting. Mouth mirror, explorer and periodontal probe were used and, the DMFT, Community Periodontal Index (CPI) (score: 0, 1, 2, 3, 4) and Oral Hygiene Index Simplified (OHI-S) (good, fair, poor) were recorded based on previously described methods $[16,17]$. The background information collected were age group, sex, education, employment and, personal and family income. The response to two questions on the selfperceived oral health status, "What is your opinion regarding the health status of your teeth?" and "What is your opinion regarding the health status of your gums?" were re-classified as "good" (initially recorded as good and very good) and "poor" (not good and bad) [18-20]. Oral health behaviours were assessed by asking about the frequency of tooth brushing (once, twice or more) and whether they had a regular dental check-up in the past year [21]. Barriers to utilization of oral health care was assessed using an open-ended question "Are there anything, such as cost, anxiety, place, illness, or other problems, that have kept you from going to the dentist?" and only the first response from the patients' own words/phrases were applied in the analysis $[22,23]$. Because the responses varied between participants and for simplicity of interpretation, the meaning of the responses were classified under 5 themes: cost, dental anxiety, social issues, distance and self-perceived. The words/phrases such as 'expensive, 'cannot afford' or 'lack of income' was represented by the cost, which reflected the high cost of treatment. The dental anxiety represented the 'shyness because of dental condition,' 'nervousness,' 'fear of dental treatment' or 'using spiritual healing'; which reflected the participants' fear of dental treatment or sought alternative treatment to avoid a dentist. The social issues represented the 'stigma', 'feeling embarrassed' and 'dependent on others for financial' or 'logistic support' to reflect the participants' feeling and esteem when they faced other people or, relied on favours from others for their needs. Responses such as 'no transportation' and 'living far from clinics' were classified as the distance; and 'health is not important' or 'no treatment needed', as the self-perceived belief that the participants did not need any dental treatment. Three burn characteristics information were obtained from the medical record; the degree of burn which described the severity of injury based on the depth of skin burned [24], the total body surface area (TBSA) affected by the injury [25] and, the time elapsed after the burn incidence. 


\section{Statistical analysis}

Summary statistics were obtained for all the variables. The t-test, ANOVA and simple linear regression (to examine the increasing trend effect) were used to examine the relationships between DMFT and the risk factors and; the chi-square test, for the CPI and OHI-S. To identify the factors associated with an overall oral health status and because the DMFT, CPI and OHI-S indices were correlated, a new parameter was derived by converting them into a single parameter clinical oral status using the component factor analysis. The procedure was applied with no rotation and one factor $($ mean $=$ $0.0, \mathrm{sd}=1, \min =-3.17, \max =1.91)$ with Eigenvalue $=$ 2.5 that explained $82.8 \%$ of the variance was extracted and saved. An increasing value of the parameter indicated a worse clinical oral status. It was then used as an outcome variable in the multiple linear regression analysis to identify the factors that influence oral health in burn patients using the stepwise method with pinclusion $=$ 0.05 , and $p_{\text {removal }} \geq 0.1$. All analysis was performed at $5 \%$ significance level and carried out in IBM SPSS software version 22.0.

\section{Results}

A total of 300 subjects were approached and, only 271 (90.3\% response rate) had consented and completed the oral examination and questionnaires. The majority of the sample were females, between 15 and 34 years-old, had less than 12 years of schooling, unemployed and from the low-income background (less than 24,000 PKR for both personal and family income) (Table 1). There were slightly greater percentages of participants who had the second degree burn (52\%), 10-20\% TBSA (54\%) and injuries that were sustained more than 3 years (54\%). Firelflames was the major cause of burn injuries in the sample (41\%).

All of the participants had caries and the mean DMFT was $10.96(\mathrm{sd}=2.41)($ Table 1$)$. About $59 \%$ of the participants had periodontal pocket greater than $4 \mathrm{~mm}$ in at least one site and $66 \%$ had poor oral hygiene. In contrast to the clinical indices, the percentage of the participants who perceived their dental (79\%) and periodontal (80\%) health as poor was greater. The majority had practised tooth brushing once a day (78\%) and did not visit a dentist in the past year for a regular checkup (89\%). Forty-six percent of the participants cited dental anxiety as the primary reason for not visiting a dentist, followed by cost $(25 \%)$ and social issues $(16 \%)$.

The results in Table 2 showed that poorer caries severity periodontal and oral hygiene statuses were significantly associated with the burn characteristics, oral health behaviours and age $(p<0.001)$. The participants with a more severe degree of burn and TBSA, and the longer time elapsed since the burn incident, practiced tooth brushing once a day and did not visit a dentist in the past year had greater mean DMFT, CPI $>2$ and poor OHI-S score; compared to the corresponding counterparts. Older participants had poorer caries severity and, periodontal and oral hygiene statuses. Caries severity was poorer in males than females. The perceived dental and periodontal status was not associated with any of the factors. The participants who cited dental anxiety as the primary barrier to the utilization of oral health care services had the greatest mean DMFT and a greater percentage of them had periodontal pockets and poor oral hygiene statuses.

The multiple linear regression analysis showed that the burn severity, time of incidence age and dental anxiety were statistically and significantly associated with worse clinical oral status and, more frequent brushing and regular dental check-ups were associated with better clinical outcomes in the burn patients (Table 3). Because both of the burn severity and TBSA were strongly correlated $(0.86, p<0.001)$, the latter were excluded from the model presented in Table 3. An alternative model that replaced the burn severity with the TBSA showed a slightly smaller but significant effect (regression coefficient $=0.23,95 \% \mathrm{CI}: 0.08,0.38, p=0.002$ ) and very little change to the other covariates.

\section{Discussion}

This report is the first to describe the oral health status of burn patients and focussed on severe cases of orofacial burn from a single burn centre. The greater percentage of second degree burn cases in the sample, which was mostly due to fire and scalding, was consistent with earlier reports [26-28]. The percentage of patients with $10-20 \%$ total body surface area (TBSA) burned in the sample was similar to studies in Sweden and the USA $[29,30]$ but lower compared to other regional studies where the cases with TBSA greater than $20 \%$ were more prevalent $[25,31]$. However, the variation could be due to the inclusion criteria that the orofacial is affected [27].

The participants were found to be burdened with caries, periodontal disease and poor oral hygiene. Because there was no earlier report on the oral health status of burn patients in the literature, it was not possible to contrast their status to any population. It is also not clear from this study whether the status had deteriorated after the burn incident. But the DMFT was, however, found to be significantly greater (mean DMFT $=8.02$, $p<0.01$ ), and the percentage of those with deep periodontal pocket $(\mathrm{CPI} \geq 3)$ was 1.5 times greater $(35.5 \%$, $p<0.05)$, than that reported in a previous study in Pakistan [14]. The perceived dental and periodontal statuses reported by the participants were not consistent with the clinical indices. Further examination of the data 
Table 1 Sociodemographic characteristics of the participants $(N=271)$

\begin{tabular}{ll}
\hline Characteristics & Number (\%) \\
\hline Age & \\
$15-24$ & $89(32.8)$ \\
$25-34$ & $125(46.1)$ \\
$35-44$ & $40(14.8)$ \\
$45+$ & $17(6.3)$
\end{tabular}

Gender

Male

85 (31.4)

Female

Education level

$0-5$ years of schooling

6-12 years of schooling

$13+$ years of schooling

Employment status

Full time job

Part time job

Unemployed

Others (student, retired)

Personal income (PKR)

$$
5000-14,000
$$

$15,000-24,000$

25,000-34,000

$35,000+$

Family income (PKR)

$15,000-24,000$

$25,000-34,000$

$35,000+$

Degree of burn injury

Second degree burn

Third degree burn

Total body surface area (TBSA)

10-20\% TBSA

More than 20\% TBSA

Time of incident

$$
1-2 \text { years }
$$

2-3 years

3-4 years

$4+$ years

Causes of burn injury

$$
\begin{aligned}
& \text { FirelFlame } \\
& \text { Scald } \backslash \text { Stream } \\
& \text { Chemicallassault } \\
& \text { Electricallothers } \\
& \text { DMFT, mean (SD) }
\end{aligned}
$$

$141(52.0)$

$130(48.0)$

$146(53.9)$

$125(46.1)$

47 (17.3)

78 (28.8)

105 (38.7)

$41(15.1)$

\begin{tabular}{|c|c|}
\hline Characteristics & Number (\%) \\
\hline \multicolumn{2}{|l|}{$\mathrm{CPI}$} \\
\hline Bleeding & $31(11.4)$ \\
\hline Calculus & $80(29.5)$ \\
\hline 4-5 $\mathrm{mm}$ pockets & $117(43.2)$ \\
\hline $6 \mathrm{~mm}$ and more pockets & $43(15.9)$ \\
\hline \multicolumn{2}{|l|}{ OHI-S } \\
\hline Good & $7(2.6)$ \\
\hline Fair & $85(31.4)$ \\
\hline Poor & $179(66.1)$ \\
\hline \multicolumn{2}{|l|}{ Self-perceived dental health } \\
\hline Good & $58(21.4)$ \\
\hline Poor & $213(78.6)$ \\
\hline \multicolumn{2}{|c|}{ Self-perceived periodontal health } \\
\hline Good & $55(20.3)$ \\
\hline Poor & $216(79.7)$ \\
\hline \multicolumn{2}{|c|}{ Daily frequency of toothbrushing } \\
\hline One time & $212(78.2)$ \\
\hline Two times & $59(21.8)$ \\
\hline \multicolumn{2}{|l|}{ Regular check-up } \\
\hline Yes & $29(10.7)$ \\
\hline No & $242(89.3)$ \\
\hline \multicolumn{2}{|c|}{ Barriers to utilization of oral health care services } \\
\hline Cost & $68(25.1)$ \\
\hline Distance & $25(9.2)$ \\
\hline Psychological & $125(46.1)$ \\
\hline Social & $42(15.5)$ \\
\hline Self-perceived & $11(4.1)$ \\
\hline
\end{tabular}

$112(41.3)$

$77(28.4)$

$58(21.4)$

$24(8.8)$

$11.0(2.4)$
Table 1 Sociodemographic characteristics of the participants $(N=271)$ (Continued)

showed that the participants who rated their dental health as good had overestimated their status where the DMFT (mean $=11.2$, sd $=2.02, n=58$ ) was not different from those who rated it as poor $($ mean $=10.9$, sd $=2.51$, $n=213$ ). And similarly, from the $20 \%$ of the participants who rated their periodontal health as good, none actually has had a clinically healthy periodontium $(\mathrm{CPI}=0)$. Thus, suggesting that the assessment of oral health status using a perceived measure may not be a reliable indicator for this community.

The analysis found two important factors associated with poor oral health status in burn patients. First is the characteristics of burn injury where the participants with greater severity of burn and amount of burnt skin area, and the longer time elapsed since the burn incident had a worse oral health status. Scarring of the skin, muscles and mucosa due to burn does not only leave an unfavourable physical appearance on the oro-facial area, 


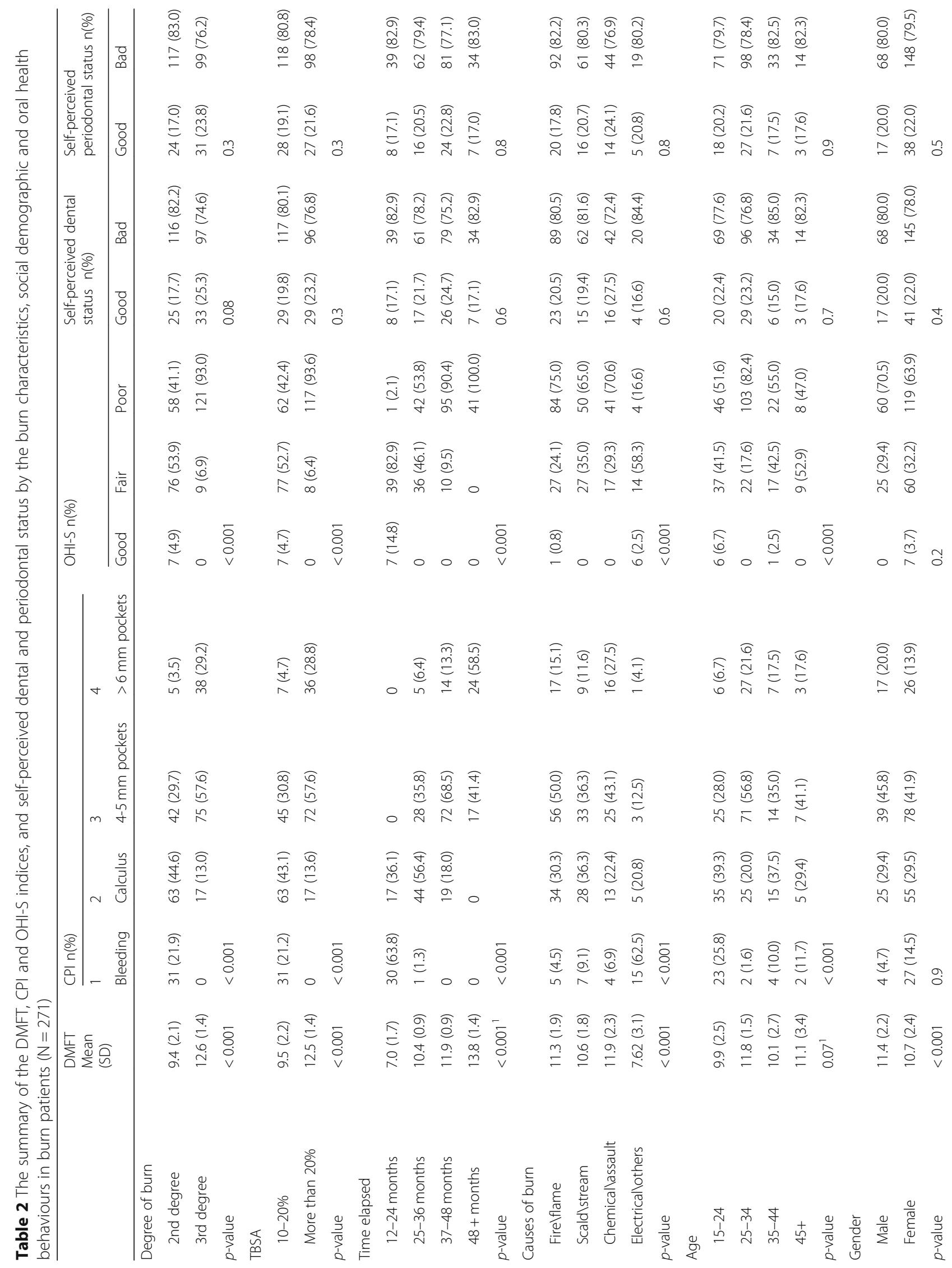




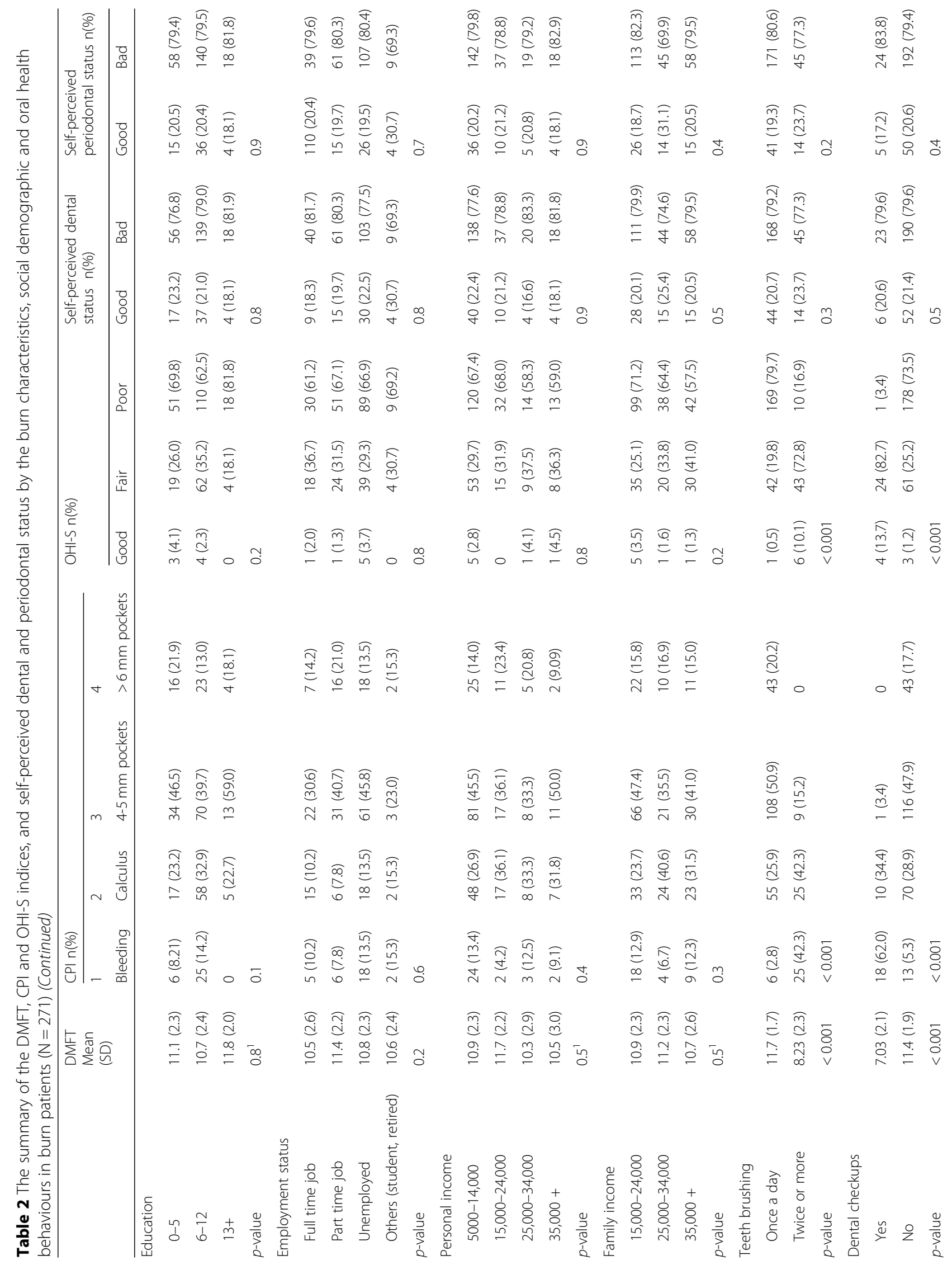




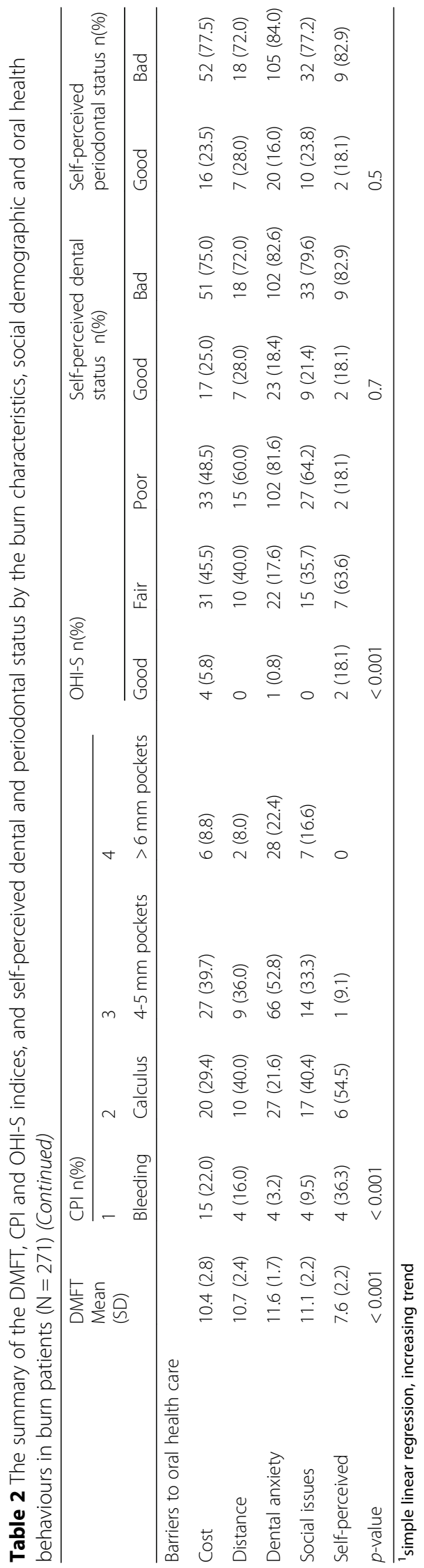


Table 3 Regression coefficient (b) of univariate and multiple linear regressions of the analysis of risk factors for clinical oral status parameter in burn patients $(\mathrm{N}=271)$

\begin{tabular}{|c|c|c|c|c|}
\hline \multirow[b]{2}{*}{ Degree of burn (Third) } & \multirow{2}{*}{$\begin{array}{l}\text { Univariate analysis b }(95 \% \mathrm{Cl}) \\
1.29(1.11,1.47)^{2}\end{array}$} & \multicolumn{2}{|c|}{$\begin{array}{l}\text { Regression coefficient for the multiple regression } \\
\text { analysis, b }(95 \% \mathrm{Cl})\end{array}$} & \multirow{2}{*}{$\begin{array}{l}\text { Standardized regression coefficient, } b \\
0.15\end{array}$} \\
\hline & & $0.30(0.15,0.45)$ & $<0.001$ & \\
\hline TBSA (More than 20\%) & $1.24(1.05,1.42)^{2}$ & - & - & - \\
\hline Time of incident ${ }^{1}$ & $0.89(0.82,0.96)^{2}$ & $0.60(0.51,0.69)$ & $<0.001$ & 0.57 \\
\hline $\mathrm{Age}^{1}$ & $0.16(0.02,0.30)^{2}$ & $0.10(0.03,0.16)$ & 0.004 & 0.08 \\
\hline Teeth brushing (twice) & $-1.51(-1.74,-1.28)^{2}$ & $0.29(-0.47,-0.11)$ & 0.002 & -0.12 \\
\hline Dental checkups (yes) & $-1.81(-2.13,-1.49)^{2}$ & $0.53(-0.75,-0.31)$, & $<0.001$ & -0.16 \\
\hline \multirow{2}{*}{\multicolumn{5}{|c|}{$\begin{array}{l}\text { Barriers to oral health } \\
\text { care }^{3}\end{array}$}} \\
\hline & & & & \\
\hline Cost & $-0.74(-1.01,-0.47)^{2}$ & - & & \\
\hline Distance & $-0.53(-0.93,-0.13)^{2}$ & - & & \\
\hline Dental anxiety & $0.35(0.19,0.52)^{2}$ & $0.21(0.09,0.33)$ & $<0.001$ & 0.11 \\
\hline Social issues & $-0.34(-0.66,-0.17)^{2}$ & - & & \\
\hline Self-perceived & $-1.67(-2.24,-1.11)^{2}$ & - & & \\
\hline Gender (Female) & $-0.29(-0.55,-0.04)^{2}$ & - & & \\
\hline Education (trend) ${ }^{1}$ & $-0.00(-0.22,0.21)$ & - & & \\
\hline \multicolumn{5}{|l|}{ Employment $^{3}$} \\
\hline Unemployed & $-0.03(-0.20,0.138)$ & - & & \\
\hline Full time & $-0.06(-0.39,0.27)$ & & & \\
\hline Part time & $-0.09(-0.66,0.49)$ & & & \\
\hline Others (student / retired) & $0.17(-0.11,0.46)$ & & & \\
\hline Personal income ${ }^{1}$ & $-0.03(-0.16,0.10)$ & - & & \\
\hline Family income $e^{1}$ & $-0.07(-0.21,0.07)$ & - & & \\
\hline
\end{tabular}

but it may also distort and limit mouth opening, lead to microstomia and cause pain on forced-opening. During the oral examination of this study, the researcher had noticed that a number of participants were uncomfortable and in pain when they were asked to open their mouth wide and for too long and; because of that a detailed intraoral examination and maxillofacial mobility and function parameters that have been planned earlier were excluded to minimise assessment time and discomfort. The similar pain could limit access to the oral cavity and makes oral hygiene practice uncomfortable and inefficient. Patients with an extended burn injury to the upper limbs, hands and fingers could have a greater disadvantage to carry out oral hygiene care effectively and could partly explain the lower frequency of brushing in the sample [32, 33]. It is also plausible, in really severe burn cases where the salivary glands are affected, that the salivary flow is reduced and the longer time elapsed after the burn incident only increases the period of exposure of the teeth and oral structures to plaque and the risk of developing caries [34]. Changes to facial appearance could also impact on self-esteem and depression and; these have been reported to affect health behavior [35]. These, however, are not captured in the present study.

The second factor associated with poor oral health status is the oral health behaviours of burn patients. The analysis suggested that good oral hygiene practices, as simple as brushing twice or more per day, and regular dental visits have a protective effect on burn patients, consistent previous studies [36, 37]. However, the majority of the participants in this study did not visit a dentist in the past year despite their poor oral health condition and the most likely explanation is dental anxiety. When asked about the reason for not utilizing the dental health services, majority of the participants cited dental anxiety as the primary barrier; and they also had the worst oral health condition compared to those who cited other reasons. Previous studies had reported associations between dental anxiety and depression and, lower frequency of dental visit [38-40]. Being outside the house will expose the facial burn patients to the public and less familiar social environment, and in the context of the local society, this could make them feel uncomfortable, anxious, embarrassed and depressed and, hence, avoid travelling to the dentist [41-44]. The cost of dental 
care is another barrier and was a concern to those from the lower socioeconomic background. The high cost of dental treatment could be an additional burden to the patients and their families on top of the expenses spent on treatment and hospitalization costs for the injury [45, 46]. Because of these reasons, the burn patients is missing out the professional help that could improve their knowledge, awareness and skill to take care of their oral health.

It can be deduced from this study that oral health behaviours are important determinants of the oral health status of burn patients in Pakistan. To overcome the issue, in tandem with individual self-care, the health professionals involved in the rehabilitation of burn patient should be informed about the risks of oral diseases and encourage them to refer the case; although this could be difficult because the current system protocol is deficient [47]. Additionally, the health system authorities could provide a friendly environment and atmosphere for the patients; for example, by having trained health professionals who understand their needs. However, a few issues are still not clear. It is a question whether the participants were dentally fit before the burn incidence and their status deteriorated because of it. It is also unclear if an oro-facial burn patient is referred to a dentist for a consultation immediately after the burn treatment completes. Studies on the relationship between oral health of burn patients and, oral health related quality of life and psychological status relating to facial appearance such as self-esteem and depression are on-going as part of the current investigation (drafts).

Originality is one of the strength of this study as it explored a niche oral health issue in a relatively small and less attended community. The study included a wide range of cases from the largest burn care centre that accepted patients from nationwide, hence may represent, to an extent, the oro-facial burn patients in general but limited to the Pakistani population. The results of this study should be interpreted with caution because of several limitations that may biased the results. The absence of information on the dental status before the burn event and cross-sectional study design limits the causal and temporal inference that the burn event is responsible for the outcomes in the patients. One of the challenging issues in this study is that much persuasion, assurance and patience are required to get the participation because the patients were psychologically and socially disturbed, hesitant, resistant, shy and afraid. It was difficult to obtain the correct and accurate information from the patients because these and, also due to pain as mentioned earlier and their educational background. Hence, the data collection process was one of the most difficult phases in the study as it was a complex, time consuming and exhausting procedure to be carried out while keeping the participants comfortable.
Because of these and cost of travelling, the burn patient were not willing to and; for those who were given an appointment, did not; return for clinical reassessment, hence the reliability study was not carried out. Another potential bias is from the self-reported health behaviours and barriers to health care utilization where the participants had to recall events that occurred in the past year. For the barriers to utilization of health care, the use of the first response only in the analysis may underestimate the effect of the themes because a similar response that is repeated as a second response was not included.

\section{Conclusion}

This study showed that patients with oro-facial burn injury have poor oral health status and that oral health behaviours, particularly the oral hygiene practice, dental visits and dental anxiety are the main modifiable factors that influence their oral health status. Referring the burn patients to a dentist at an early stage may prevent further deterioration of oral health, thus should be part of the post-emergency burn care.

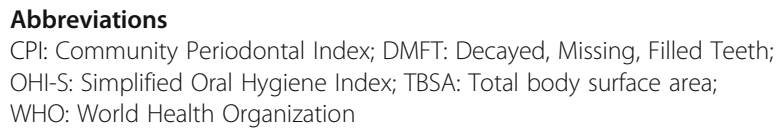

\section{Acknowledgements}

The authors would like to express their gratitude to the Burn Care Center, Pakistan Institute of Medical Sciences, Islamabad, Pakistan and all the burn patients who participated in this study.

\section{Authors' contributions}

FAC collected the data and performed data analyses and wrote the first draft of the manuscript. BA was involved in the conceptual development of this paper and provided feedback and revised the final manuscript. UB

supervised and contributes in the data collection process. All authors read and approved the final manuscript.

\section{Funding}

No specific funding was obtained for this study.

\section{Availability of data and materials}

At present, the data related to the report is available upon reasonable request from the corresponding author because it is linked to a larger dataset of a PhD project which further reports are being prepared. It is the intention to make the whole dataset available on a platform such as the BMC Research Notes after the reports are completed.

\section{Ethics approval and consent to participate \\ This study has been approved by the Ethical Review Board, Pakistan Institute of Medical Sciences, Shaheed Zulfiqar Ali Bhutto Medical University in accordance with the Helsinki Declaration (Reference no. F.1-1/2015/ERB/ SZABMU). Written informed consent has been obtained from the participants prior to data collection process and, the data were anonymized before analysis.}

\section{Consent for publication}

Not applicable.

Competing interests

The authors declare that they have no competing interests. 


\section{Author details}

${ }^{1}$ Dental College, HITEC Institute of Medical Sciences, Taxila, Pakistan. ${ }^{2}$ School of Dental Sciences, Universiti Sains Malaysia, Kubang Kerian, Malaysia. ${ }^{3}$ Islamic International Dental College, Riphah International University, Islamabad, Pakistan

Received: 28 March 2019 Accepted: 9 June 2019

Published online: 26 June 2019

\section{References}

1. Ahuja RB, Bhattacharya S. Burns in the developing world and burn disasters. Bmj. 2004;329(7463):447-9.

2. Forjuoh SN. Burns in low-and middle-income countries: a review of available literature on descriptive epidemiology, risk factors, treatment, and prevention. Burns. 2006;32(5):529-37.

3. Wust KJ. A modified dynamic mouth splint for burn patients. J Burn Care Res. 2006;27(1):86-92.

4. Bahnof R. Intra-oral burns: rehabilitation of severe restriction of mouth opening: case report. Physiotherapy. 2000;86(5):263-6.

5. Dougherty M, Warden G. A thirty-year review of oral appliances used to manage microstomia, 1972 to 2002. J Burn Care Res. 2003;24(6):418-31.

6. Johnson J, Candia J, LaTrenta G, Madden MR, Goodwin CW, Finkelstein J: A nasal trumpet orthosis to maintain nares openings and respiratory function for patients with facial burns: a case report. J Burn Care Rehabil 1992, 13:677-677.

7. Clayton NA, Ledgard JP, Haertsch PA, Kennedy PJ, Maitz PK. Rehabilitation of speech and swallowing after burns reconstructive surgery of the lips and nose. J Burn Care Res. 2009;30(6):1039-45.

8. Gift HC, Atchison KA. Oral health, health, and health-related quality of life. Med Care. 1995:NS57-77.

9. Sheiham A. Oral health, general health and quality of life. Bull World Health Organ. 2005:83(9):644.

10. Saffle JR. Predicting outcomes of burns. N Engl J Med. 1998;338(6):387-8.

11. Druery M, Brown TLH, Muller M. Long term functional outcomes and quality of life following severe burn injury. Burns. 2005;31(6):692-5.

12. Saffle JR. Clinical research in burns: state of the science, 2006. J Burn Care Res. 2007;28(4):546-8.

13. Magnani DM, Sassi FC, Vana LPM, Alonso N, Andrade CRF. Evaluation of oral-motor movements and facial mimic in patients with head and neck burns by a public service in Brazil. Clinics. 2015;70(5):339-45.

14. Bokhari SAH, Suhail AM, Malik AR, Imran MF. Periodontal disease status and associated risk factors in patients attending a dental teaching Hospital in Rawalpindi, Pakistan. J Indian Soc Periodontol. 2015;19(6):678.

15. Veerasamy A, Kirk R, Gage J. Epidemiology of dental caries among adolescents in Tamil Nadu, India. Int Dent J. 2016;66(3):169-77.

16. WHO. World Health Organization, Oral health surveys: basic methods. Geneva: World Health Organization; 1997. p. 1997.

17. Greene JG, Vermillion JR. The simplified oral hygiene index. J Am Dent Assoc. 1964;68(1):7-13.

18. Zini A, Vered $Y$, Sgan-Cohen HD. Are immigrant populations aware about their oral health status? A study among immigrants from Ethiopia. BMC Public Health. 2009:9(1):1

19. Kojima A, Ekuni D, Mizutani S, Furuta M, Irie K, Azuma T, Tomofuji T, Iwasaki $Y$, Morita M. Relationships between self-rated oral health, subjective symptoms, oral health behavior and clinical conditions in Japanese university students: a cross-sectional survey at Okayama University. BMC oral health. 2013;13(1):1.

20. Furuta M, Ekuni D, Takao S, Suzuki E, Morita M, Kawachi I. Social capital and self-rated oral health among young people. Community Dent Oral Epidemiol. 2012;40(2):97-104.

21. Furuta M, Ekuni D, Irie K, Azuma T, Tomofuji T, Ogura T, Morita M. Sex differences in gingivitis relate to interaction of oral health behaviors in young people. J Periodontol. 2011;82(4):558-65.

22. Drake CW, Beck JD, Strauss RP. The accuracy of oral self-perceptions in a dentate older population. Spec Care Dentist. 1990;10(1):16-20.

23. Patton LL, Strauss RP, McKaig RG, Porter DR, Eron JJ Jr. Perceived oral health status, unmet needs, and barriers to dental care among HIV/AIDS patients in a North Carolina cohort: impacts of race. J Public Health Dent. 2003:63(2):86-91

24. Torpy JM, Lynm C, Glass RM: Burn Injuries. JAMA 2009, 302(16):1828-1828.
25. Lari AR, Alaghehbandan R, Nikui R. Epidemiological study of 3341 burns patients during three years in Tehran, Iran. Burns. 2000;26(1):49-53.

26. Khaliq MF, Noorani MM, Siddiqui UA, Al Ibran E, Rao MH. Factors associated with duration of hospitalization and outcome in burns patients: a cross sectional study from government tertiary Care Hospital in Karachi, Pakistan. Burns. 2013;39(1):150-4.

27. Edwardson A. Characteristics of Female Burns in In-patients: An analysis of burn causes, injured areas and duration of treatment. Lithuanian University of Health Sciences. Department of Plastic and Reconstructive Surgery; 2017. http://repository.Ismuni.lt/handle/1/33593

28. Mohebbi Z, Najafi S, Molazem Z, Setoodeh G. Epidemiology, causes and outcome of burns in women from southern Iran: 2009-2011. Women's Health Bulletin. 2014;1(2)

29. Åkerlund E, Huss FR, Sjöberg F. Burns in Sweden: an analysis of 24538 cases during the period 1987-2004. Burns. 2007:33(1):31-6.

30. Modjarrad K, McGwin G Jr, Cross JM, Rue LW III. The descriptive epidemiology of intentional burns in the United States: an analysis of the National Burn Repository. Burns. 2007:33(7):828-32.

31. Ali S, Hamiz-ul-Fawwad S, Al-lbran E, Ahmed G, Saleem A, Mustafa D, Hussain M. Clinical and demographic features of burn injuries in Karachi: a six-year experience at the burns Centre, civil hospital, Karachi. Ann Burns Fire Disasters. 2016:29(1):4.

32. Johnson SP, Chung KC. Outcomes assessment after hand burns. Hand Clin. 2017:33(2):389-97.

33. Perera M, Nanayakkarawasam $P$, Katulanda P. Effects of burn on the mobility of upper limb/s, functions of hand/s \& activities of daily living. Int $J$ Physiother Res. 2015;3(1):832-8.

34. Lazaridou M, Iliopoulos C, Antoniades K, Tilaveridis I, Dimitrakopoulos I, Lazaridis N. Salivary gland trauma: a review of diagnosis and treatment. Craniomaxillofac Trauma Reconstr. 2012;5(04):189-96.

35. Jain M, Khadilkar N, De Sousa A. Burn-related factors affecting anxiety, depression and self-esteem in burn patients: an exploratory study. Ann Burns Fire Disasters. 2017:30(1):30.

36. Batista MJ, Lawrence HP, de Sousa MLR. Oral health literacy and oral health outcomes in an adult population in Brazil. BMC Public Health. 2018;18(1):60.

37. Soroye MO, Braimoh BO. Oral health practices and associated caries experience among secondary school students in Lagos state, Nigeria. J Oral Res Rev. 2017;9(1):16

38. Nicolas E, Collado V, Faulks D, Bullier B, Hennequin M. A national crosssectional survey of dental anxiety in the French adult population. BMC Oral Health. 2007;7(1):12

39. Appukuttan D, Subramanian S, Tadepalli A, Damodaran L. Dental anxiety among adults: an epidemiological study in South India. N Am J Med Sci. 2015;7(1):13-8.

40. Anttila S, Knuuttila M, Ylöstalo P, Joukamaa M. Symptoms of depression and anxiety in relation to dental health behavior and self-perceived dental treatment need. Eur J Oral Sci. 2006;114(2):109-14.

41. Sohn W, Ismail Al. Regular dental visits and dental anxiety in an adult dentate population. J Am Dent Assoc. 2005;136(1):58-66.

42. Schuller AA, Willumsen T, Holst D. Are there differences in oral health and oral health behavior between individuals with high and low dental fear? Community Dent Oral Epidemiol. 2003;31(2):116-21.

43. Ferrer RA, Klein WM. Risk perceptions and health behavior. Curr Opin Psychol. 2015;5:85-9.

44. Jagnoor J, Bekker S, Chamania S, Potokar T, Ivers R. Identifying priority policy issues and health system research questions associated with recovery outcomes for burns survivors in India: a qualitative inquiry. BMJ Open 2018;8(3):e020045

45. Mashreky SR, Rahman A, Chowdhury S, Giashuddin S, Svanström L, Khan T, Cox R, Rahman F. Burn injury: economic and social impact on a family. Public Health. 2008;122(12):1418-24.

46. Mirastschijski U, Sander J-T, Weyand B, Rennekampff H-O. Rehabilitation of burn patients: an underestimated socio-economic burden. Burns. 2013;39(2):262-8.

47. Naumeri F, Ahmad Al, Ahmad HM, Malik U, Sarwar MZ. An evaluation of management of transferred paediatric burn patients. J Pak Med Assoc. 2018;68(5):787-9.

\section{Publisher's Note}

Springer Nature remains neutral with regard to jurisdictional claims in published maps and institutional affiliations. 